\title{
EDITORIAL
}

\section{The 阴阳 of COPD: or balancing repair (yang) and inflammation (yin)}

\author{
J.B. Soriano ${ }^{*, \#}$ and A. Agustí*,\#,"
}

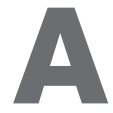

ncient Chinese scholars believed there were two natural, complementary and contradictory forces in our universe: yin and yang (or in simplified Chinese 阴阳, in traditional Chinese 陰陽, and in pinyin (standard Mandarin romanisation) yīnyáng). Yin represents the female, negative aspects, darkness, softness, moisture, night-time, even numbers, and docility. Yang represents the male, positive aspects, brightness, hardness, dryness, day-time, odd numbers, and dominance. Yin and yang are continually in a state of flux and always looking for a balance point. One moves, the other responds. Ancient scholars therefore treated this phenomenon as a natural universal law.

In this issue of the European Respiratory Journal (ERJ), MAN et al. [1] hypothesise that a ratio of fibronectin to C-reactive protein (CRP) is a more suitable tool than each separated biomarker to assess the prognosis of chronic obstructive pulmonary disease (COPD). Using the Lung Health Study III data [2], they updated (and improved on) their previous research on CRP only [3]. It appears that in this well-described group of mild-tomoderate COPD patients, the relationship of the log transformed ratio of fibronectin to CRP (both in $\mathrm{ug} \cdot \mathrm{mL}^{-1}$ ) and mortality is L shaped, and that beyond a threshold set around 150 , there were virtually no deaths observed. If this simple idea proved true, it could have tremendous prognostic implications. Mathematically, in any L shape relationship with an adverse outcome, the higher the ratio, the better [4]. In a ratio of fibronectin to CRP, this could happen either through a higher fibronectin concentration (more repair) or through a lower CRP (less inflammation).

Naturally, the study by MAN et al. [1] is hypothesis-generating and deserves to be tested in other samples of COPD individuals with a more varied severity and from different settings.

The research by MAN et al. [1] is opportunistic as data were collected for a different purpose in an original clinical trial [5], so the study in the present issue of the ERJ has intrinsic limitations, some of them already highlighted by the authors. As in any cross-sectional analysis, causality cannot be inferred.

\footnotetext{
*Epidemiology and Clinical Research, CIMERA, Recinte Hospital Joan March, Bunyola, Spain. ${ }^{\#}$ CIBER de Enfermedades Respiratorias. "Pneumology Dept, Hospital Universitari Son Dureta, Palma Mallorca, Spain.
}

STATEMENT OF INTEREST: None declared.

CORRESPONDENCE: J.B. Soriano, Epidemiology and Clinical Research, CIMERA, Recinte Hospital Joan March, Carretera Soller Km 12, 07110 Bunyola, Spain. Fax: 34 971148442. E-mail: jbsoriano@caubet-cimera.es
Whether a COPD phenotype expressing more inflammation and/or less repair is associated with a higher likelihood of death, could be a spurious association or a consequence rather than a cause. Whether or not plasma measurements of CRP and fibronectin really reflect what is occurring in the lungs is speculative, and the precise role of both molecules in the process of lung (not plasma) damage and repair is still poorly defined. In fact, acute inflammation is the first step of a successful repair process [6] and a clear-cut separation between the two processes is blurred. As MAN et al. [1] discuss, measurements were taken at a single time-point, so the reproducibility of this ratio as well as their direct relationship to other important dimensions of the disease has to be explored. In fact, there was no consistency of the reported association with decline in lung function or respiratory-specific mortality (communication from the authors), which is in contradiction with the initial hypothesis. Finally, the patients studied by MAN et al. [1] had mild-to-moderate COPD; results may therefore be different in patients with more severe disease. Nevertheless, this is an important study as it opens a new avenue for research, to address the limitations and/or test the validity of other molecules that can better reflect this yīnyáng of COPD [7].

The search for COPD biomarkers is a race, and some of the rules for assessment and use of current and future outcomes and markers have been set [8]. The study by MAN et al. [1] may encourage others to help disentangle the controversy regarding whether inflammation and repair are friend or foe [9-11]. Some remaining unknowns, and some possible ways to tackle them, have been listed elsewhere [12]. Very recently, CURTIS et al. [13] proposed and substantiated another hypothesis on the pathogenesis of COPD, christened the "Goldilocks" hypothesis. Basically, this hypothesis states that there is no such thing as bad inflammation; it all depends on how and when, just as in the children's fairy tale. "Too little" or "too much" of repair and inflammation during given windows of the growing, mature or ageing lung, might relate to the success of the adaptive immune response in controlling the innate response. On the one hand, this could produce progression of the natural history of COPD as we currently understand it; on the other, it might explain some "healthy" smokers who have normal lung function after many pack-yrs of tobacco exposure. Even the noninflammatory state might not arise passively from an absence of inflammatory stimuli; rather, maintenance of health might require the positive actions of specific gene products to suppress reactions to potentially inflammatory stimuli that do not warrant a full response [6]. 
Speculating on possible disease modification by treatment interventions would follow. The fine balance of the efficacy of any anti-inflammatory or pro-repair management and pharmacological therapy will have to be weighed against any potential adverse event related to artificially modifying a careful balance between inflammation and repair, aimed at maintaining lung homeostasis.

Almost a decade ago, RENNARD [14] indicated that repair processes after injury induced by cigarette smoking can lead to healing or more disease, and suggested that whether injury results in an accumulation of abnormal fibrotic tissue is likely to depend on a complex balance of factors derived from several sources. As in the yīnyáng symbology, it is likely that repair and inflammation in chronic obstructive pulmonary disease are interconnected in a complex manner, with positive and negative feedback at different times and conditions. Each of them contains an element or seed of the other, and they cannot exist without each other.

\section{REFERENCES}

1 Man SFP, Xing L, Connett JE, et al. Circulating fibronectin to C-reactive protein ratio and mortality: a biomarker in COPD? Eur Respir J 2008; 32: 1451-1457.

2 Anthonisen NR, Skeans MA, Wise RA, Manfreda J, Kanner RE, Connett JE. The effects of a smoking cessation intervention on 14.5-year mortality: a randomized clinical trial. Ann Intern Med 2005; 142: 233-239.

3 Man SF, Connett JE, Anthonisen NR, Wise RA, Tashkin DP, Sin DD. C-reactive protein and mortality in mild to moderate chronic obstructive pulmonary disease. Thorax 2006; 61: 849-853.
4 Gaziano JM, Gaziano TA, Glynn RJ, et al. Light-tomoderate alcohol consumption and mortality in the Physicians' Health Study enrollment cohort. J Am Coll Cardiol 2000; 35: 96-105.

5 Anthonisen NR, Connett JE, Kiley JP, et al. Effects of smoking intervention and the use of an inhaled anticholinergic bronchodilator on the rate of decline of FEV1. The Lung Health Study. JAMA 1994; 272: 1497-1505.

6 Nathan C. Points of control in inflammation. Nature 2002; 420: 19-26.

7 Franciosi LG, Page CP, Celli BR, et al. Markers of disease severity in chronic obstructive pulmonary disease. Pulm Pharmacol Ther 2006; 19: 189-199.

8 Cazzola M, MacNee W, Martinez FJ, et al. Outcomes for COPD pharmacological trials: from lung function to biomarkers. Eur Respir J 2008; 31: 416-469.

9 Brusasco V, Crimi E, Pellegrino R. Airway inflammation in COPD: friend or foe? Am J Respir Crit Care Med 2007; 176: 425-426.

10 Vestbo J. Systemic inflammation and progression of COPD. Thorax 2007; 62: 469-470.

11 Agustí A, Soriano JB. COPD as a systemic disease. COPD 2008; 5: 133-138.

12 Agustí A. Systemic effects of chronic obstructive pulmonary disease: what we know and what we don't know (but should). Proc Am Thorac Soc 2007; 4: 522-525.

13 Curtis JL, Freeman CM, Hogg JC. The immunopathogenesis of chronic obstructive pulmonary disease: insights from recent research. Proc Am Thorac Soc 2007; 4: 512-521.

14 Rennard SI. Inflammation and repair processes in chronic obstructive pulmonary disease. Am J Respir Crit Care Med 1999; 160: S12-S16. 